\title{
AN ECONOMETRIC MODEL OF THE TEXTILE INDUSTRY IN THE UNITED STATES ${ }^{1}$
}

\author{
William H. Wallace, Thomas H. Naylor, and W. Earl Sasser *
}

\section{Introduction}

$\mathrm{T}$ $\mathrm{HE}$ model presented in this paper is a system of recursive linear regression equations, the parameters of which are estimated from monthly series of data covering the period, January, 1951, through December, 1962. The parameters relate certain exogenous and predetermined endogenous variables to apparel demand, apparel output, textile demand, textile output, and employment, earnings, prices, profit, and investment for the textile industry. Elsewhere [9] the authors use this model to simulate the aggregate behavior of the industry for the 1951-1962 period and for 1963 through 1964.

There are a number of problems and characteristics which are unique to textile manufacturing in the United States. They are frequently brought to the attention of the public as a result of the industry's extreme sensitivity to such things as changes in tariffs, changes in wage levels, and changes in government price policies on cotton. Imports of textiles, for example, have been troublesome to American textile producers due to low wages abroad and the development of a large and efficient productive capacity in many foreign countries. This situation has been the subject of considerable controversy in recent months due to the expiration of the Long Term Arrangement on trade in cotton textiles $[7,21]$. Related to the import problem is the problem of cotton prices. The introduction of one-price cotton in April,

\footnotetext{
* The authors are respectively Assistant Vice-President and Economist, Federal Reserve Bank of Richmond; Associate Professor of Economics, Duke University; Research Assistant in Economics, Duke University.

${ }^{1}$ Econometric System Simulation Program, Working Paper No. 7, July 1, 1967.

This research was supported by grants from the National Science Foundation (GS-1104), and the Duke University Research Council. It is part of a collection of studies entitled, "Design of Computer Simulation Experiments for Economic Systems."

The authors are indebted to Dr. R. Buford Brandis, of the American Textile Manufacturers Institute and Dr. Thomas Wonnacott of Duke University, for suggestions and assistance.
}

1963, ended a dual-price system, in effect since 1956, which had caused producers of the United States to pay higher prices for inputs than foreign producers.

In addition to these economic variables which are subject to control largely by public policy or by bargaining, there are other characteristics of the industry which have contributed to its historical instability. Evidence of this has been the two-year textile cycle which persisted in the output of textile mill products, even in spite of a relatively stable end-use demand. ${ }^{2}$ Several previous studies have noted the damaging effect of this cyclical pattern upon the industry [1, $6,24,25]$. Stanback's analysis of the textile cycle $[14,15]$ provided reasons for this cyclical pattern, and also provided measures of the cycle for the period 1919 through 1956.

In developing an econometric model of the textile industry it was necessary to determine whether the cyclical behavior, which influenced this industry in earlier years, still prevailed. Preliminary investigations led the authors to the conclusion that there had been basic changes in the nature of the industry, such as increasing concentration, diversification of inputs, wider ownership, and more scientific management which had led to greater stability. ${ }^{3}$ These are among the features of the United

\footnotetext{
${ }^{2}$ Previous studies, for example, have shown the income elasticity of demand for apparels, one of the principal components of end-use demand for textile mill products, to be approximately equal to unity [23]. This study confirms that finding; over the period examined, the income elasticity of apparel demand was 1.05 .

${ }^{3}$ Many textile executives today deny that their firms are any longer sensitive to the textile cycle, and indeed assert that it is a thing of the past. Numerous trade association researchers concur in this opinion regarding the aggregate behavior of the industry, and state that cyclical movements in textile products appear to be approaching fluctuations in business activity generally. Other recent research on textile industry problems has also revealed this change [13].

Two applications of spectral analysis were made to the data in connection with the development of a separate paper on this subject. (See Naylor, Wallace, and Sasser [9].) The spectrum does not reveal any evidence of a special two to three-year textile cycle, nor does the analysis reveal any basic change in a cyclical pattern during this period. (For the techniques, see Granger and Hatanaka [5].)
} 
States textile industry which make it interesting as well as difficult to study.

The following model portrays this industry for a relatively recent twelve-year period, and the resulting portrayal is probably quite unlike what might have emerged from an econometric study of an earlier period in its history.

\section{The Model}

The model consists of nine linear, recursive equations, logically tied together so that the system as a whole provides explanation of the behavior of seven key endogenous variables of the textile industry, and two apparel variables. The two apparel dependent variables are intermediate in this model and are in turn used to explain textile activity, the apparel industry not being the primary object of our research. The seven dependent textile variables might be regarded as performance variables by which the economic activity of the industry is gauged. The objective of this study is to explain the determinants of change in these seven variables.

A fully developed model of foreign trade in textiles is not included in this presentation. Although this model deals essentially with the domestic industry, the effect of textile imports cannot be ignored. Increasing attention has been devoted to the growing level of imports and the threat which textile spokesmen say they pose to the domestic industry. This variable is important also due to the recent discussions regarding the continuation of the Long Term Arrangement. Therefore, an import variable is included as a determinant of domestic textile demand.

Observations are monthly, for the period January, 1951 through December, 1962. There were a number of variables and transformations of variables considered other than those which appear in the final versions of this model. However, in all such cases logic was forced to yield to tests of statistical significance, and variables were eliminated when nonsignificant.

The method used for obtaining the parameter estimates was that of ordinary least-squares for multiple linear regressions, operating separately upon each equation. ${ }^{4}$ With regard to the equations presented in this paper, each equation is

\footnotetext{
ology.
}

independent, and observed values of all dependent variables are used for parameter estimation. In the paper of Naylor, Wallace, and Sasser [9], all nine equations are allowed to operate as a system for purposes of simulation. In that case, using the parameter estimates presented in this paper, computed values of all dependent variables are obtained and these are in turn substituted for the observed values of the corresponding independent variable in each successive equation. The model, in substantially the same form as presented here, was found by three alternative tests to be satisfactory for the purpose of simulation.

The following list includes variables which appear in the textile industry model, with abbreviations and sources of the data. Unless otherwise stated, all variables are in current dollars and are unadjusted.

$D_{A}=$ Apparel retail sales in millions of dollars. (Source: Office of Business Economics (OBE)).

$A D_{A}=$ Moving average of $D_{A}$.

$D P I=$ Disposable personal income in billions of dollars. (Source: OBE).

$C P I=$ Consumer price index, 1957-1959 $=100$. (Source: U.S. Department of Labor).

$A_{D}=$ Magazine advertising for apparel and accessories in millions of dollars. (Source: OBE).

$O_{\Lambda}=$ Index of production of apparel products, $1957-1959=100$. (Source: OBE).

$A O_{A}=$ Moving average of $O_{\Lambda}$.

$I N V_{A}=$ Inventories of apparel retail stores in millions of dollars. (Source: OBE).

$D_{T}=$ Shipments of textile mill products, in billions of dollars. (Source: OBE).

$A D_{T}=$ Moving average of $D_{T}$.

$I M=$ Imports of textile fibers and manufactures, excluding raw wool and cotton. (Source: Bureau of Census).

$O_{T}=$ Index of production of textile mill products, $1957-1959=100$. (Source: OBE).

$I N V / U O=$ Ratio of inventories to unfilled orders for textile mill products. (Source: American Textile Manufactures Institute (ATMI)).

$N_{P T}=$ Production and related workers on the payrolls in textile manufacturing, in thousands. (Source: OBE).

$E_{\bar{w} / m}=$ Average weekly gross earnings per production worker in textiles, in dollars. (Source: OBE).

$P_{T}=$ Index of prices of textile products and apparel, $1957-1959=100$. (Source: U.S. Department of Labor).

$P_{w}=$ Index of wool prices, $1957-1959=100$. (Source: OBE). 
$\Pi_{T}=$ Net profit after taxes in textile mill products, in millions of dollars. (Source: Federal Trade Commission (FTC) and Secu.ities Exchange Commission (SEC)).

$I_{T}=$ Investment in new plant and equipment in billions of dollars. (Source: SEC).

$M=$ A monthly dummy variable, numbered 1 for January, 2 for February, etc., through 12 for December, similarly for each year. $T=$ A trend dummy variable, numbered 1 through 144.

\section{Behavioral Equations}

\section{Apparel Demand}

$$
\begin{aligned}
D_{A}(t)= & -553.71 \\
+ & 300.81[D P I / C P I(t-1)] \\
& (48.8) \\
+ & 96.94\left[A_{D}(t-1)\right] \\
& (12.7) \\
- & 55.19\left[A_{D}(t-2)\right] \\
& (11.3) \\
+ & 94.38\left[A_{D}(t-3)\right]+34.83[M] \\
& (12.2) \\
R & =.835 \\
F & =62.4 \\
D W & =1.70
\end{aligned}
$$

Apparel Output

$$
\begin{gathered}
O_{A}(t)=-4.38+.01824\left[A D_{A}(t)\right] \\
+30.70\left[I N V_{A}(t-1)\right] \\
(3.10) \\
R=\quad .786 \\
F=111.7 \\
D W=\quad .96
\end{gathered}
$$

Demand for Textile Mill Products

$$
\begin{aligned}
D_{T}(t)= & .7424+.0073\left[O_{A}(t)\right] \\
& (.0009) \\
- & .0084\left[A O_{A}(t)\right]+.0063[I M(t)] \\
& (.0011) \\
+ & .0141[M] \\
& (.0019) \\
R & =.0007) \\
F & =86.8 \\
D W & =1.35
\end{aligned}
$$

(1)

\section{Prices}

$$
\begin{aligned}
P_{T}(t)= & 169.07-8.41[I N V / U O(t-1)] \\
+ & .5722\left[E_{\bar{w} / m}(t)\right]+.7986\left[P_{T}(t-1)\right] \\
& (.1522) \quad(.0267) \\
+ & .0342\left[P_{w}(t-1)\right]-.0682[T] \\
& (.0093) \\
R & =.983 \\
F & =631.8 \\
D W & =1.96
\end{aligned}
$$

\section{Profit}

$$
\begin{aligned}
\Pi_{T}(t)= & -463.43+1.80\left[P_{T}(t)\right] \\
- & 1.39\left[P_{T}(t-1)\right]+41.28\left[D_{T}(t)\right] \\
& (.31) \quad(15.72) \\
- & 58.65[I N V / U O(t-1)] \\
& (9.91) \\
+ & 1.78\left[E_{\bar{w} / m}(t)\right] \\
& (.42) \\
R & =.851 \\
& F=71.9 \\
D W & =.98
\end{aligned}
$$

$$
\begin{aligned}
& \text { Output of Textile Mill Products } \\
& \qquad \begin{array}{c}
O_{T}(t)= \\
(3.2) \\
-14.45[\text { INV } / U O(t-1)] \\
(2.4) \\
-.515[M]+.082[T] \\
(.106) \quad(.009) \\
R=\quad .894 \\
F=137.3 \\
D W=1.71
\end{array}
\end{aligned}
$$

Investment

$$
\begin{gathered}
I_{T}(t)=-.1869+.2524\left[A D_{T}(t)\right] \\
+.000075[T] \\
(.000029) \\
R=.90
\end{gathered}
$$




$$
\begin{gathered}
F=274.4 \\
D W=\quad .62 \\
A D_{A}(t)=1 / 3 \sum_{r=1}^{3} D_{A}(t-r) \\
A O_{A}(t)=1 / 3 \sum_{r=1}^{3} O_{A}(t-r) \\
A D_{T}(t)=1 / 12 \sum_{r=1}^{12} D_{T}(t-r)
\end{gathered}
$$

Given with each equation are the values of $R$, the multiple correlation coefficient, and the $F$ statistic, by which the statistical significance of the total correlation of each equation is tested. For each of the nine behavioral equations, the value of $F$ is significant at the .01 level. The number in parentheses below each net regression coefficient is the standard error associated with that coefficient. Ratios for testing the significance of these coefficients, $t$ ratios, are obtained by dividing each coefficient by its standard error. On the basis of these calculations, decisions were made as to which variables to eliminate from the model. All variables remaining are significant at the .05 level, with the exception of $O_{T}(t-2)$ in equation (5) which was allowed to remain and is significant at the .06 level. Actually, only four of the thirty-four regression coefficients shown fail to be statistically significant at the .01 level.

These statistics indicate a very good fit of the conceptual model to the empirical data used. However, when using monthly timeseries data in economics, one often encounters statistical difficulties which are not revealed by such tests. Among these is the problem of autocorrelation of the residuals obtained from the estimating equations. Johnston [8] states that if one applies simple least squares to estimate the parameters of a relationship with autocorrelated residuals, then he will obtain unbiased estimators, but is likely to seriously underestimate their sampling variances. This would imply that variables in such a situation are likely to appear statistically significant when in reality they are not. Accordingly, we have calculated the Durbin-Watson statistic $(D W)$, shown for each equation, which provides a test for the presence of autocorrelation. We deal, in the final section of this paper, with a transformation of the variables in those equations which do not pass the Durbin-Watson tests, in an attempt to rid the model of the presence of autocorrelation.

Insofar as the initial version of the model is concerned, we have attempted to construct a set of equations which represents, as closely as possible, the a priori assumptions and information we have, describing the behavior of the textile industry.

Equations (1) and (2) relate to the apparel industry and are included in the model because of the close relationship between the two industries and the important way in which apparel output bears upon the demand for textile mill products. Therefore, these equations are by no means a complete representation of the apparel industry, but their purpose is to attempt to estimate independently a major component of textile demand.

Equation (1) relates apparel demand to real disposable income in the preceding month, magazine advertising for apparel and accessories for each of the three preceding months, and a monthly dummy variable which takes into account seasonal fluctuations. These results substantiate the fact that apparel sales are highly seasonal, and are influenced by income and advertising. The negative sign associated with $A_{D}(t-2)$ offers what at first appears to be a surprising result. However, upon close examination of the month-by-month swings in apparel sales, one finds the result obtained in equation (1) to be, on the average, consistent with the reported data on magazine advertising for apparels. All variables in the apparel demand equation are significant at the .01 level.

Equation (2) specifies apparel demand and retail inventories of apparels for the preceding month as the determinants of apparel output in a given month. The first of these variables is a moving average of apparel demand for the three months prior to the given month. Both variables are significant at the .01 level. Apparel output then provides the tie-in to the first of the equations representing the textile industry proper.

Equation (3) relates the demand for textile mill products, measured by monthly shipments, to apparel output in the current month, as well 
as to a moving average of apparel output in the three preceding months, current imports of finished and semifinished textile goods, and a monthly dummy variable representing seasonal variation. The presence of these four variables, all significant at the .01 level, is consistent with some interesting hypotheses.

Current apparel output is positively related to textile demand in a given month, but the moving average of apparel output for the preceding three months is negatively related to textile demand. The same kind of relationship was also observed when moving averages of apparel output for the preceding six months and for the six-month period ending six months prior to the given month were used. The threemonth moving average which appears in the equation was chosen because it is most significant in the statistical sense. In other words, increases (or decreases) in apparel output, after some lag in time, will result in decreases (or increases) in the demand for textile mill products.

Aside from apparels, there are other important components of textile demand. However, attempts to use production of automotive and home goods, industrial production generally, or exports as explanatory variables representing other components of demand in equation (3) did not result in significant relationships, and these variables were dropped from further consideration.

Another result of interest shown in equation (3) is the highly significant positive relationship between imports and textile demand. Textile demand has increased over the period covered by this study, and so have imports of textile goods. In the years since the period covered by the study, this relationship revealed by equation (3) is apparently still valid. Particularly during the years 1965 and 1966, when there was a rapidly increasing military demand for textiles, the productive capacity of the industry was not increased rapidly enough to meet this rising component of demand and increases in civilian demand due to general economic prosperity. Therefore, imports of textile goods have increased. Indeed, one might argue that had such increases in imports not occurred, the prices of textile goods in the United States would have risen sharply. It is not clear, then, that the industry's claim of injury due to imports is justifiable since the capacity to meet total demand has apparently not been available. And from the consumer's point of view, imports have been beneficial.

Equation (4) explains the output of textile mill products in terms of textile demand in the current period, the ratio of inventories to unfilled orders in the preceding period, and two dummy variables representing, respectively, the seasonal variation and the secular trend. All four of these variables are significant at the .01 level. In the introduction of this paper we have discussed the characteristic textile cycle which previously characterized the output of textile mill products. Equation (4) shows that the seasonal component of variation in output remains high. For the most part, the remaining sources of variation in textile output are explained both logically and statistically by variations in textile demand and the inventories to unfilled orders ratio.

Equation (5) indicates that employment of production workers in textiles is related to output of textile mill products in the current period and in each of the three preceding periods, as well as real disposable income. The connection between production worker employment and current and recent levels of output is a logical one. However, the relation between employment and aggregate real income, which is negative and significant at the .01 level, provides an interesting insight into a long-run development within the textile industry. Employment of production workers in the textile industry has declined by over 300,000 during the 12-year period covered by this study, while output has significantly increased. Automation has taken place to a large extent, and provides a partial explanation, but the cause and effect relationship between these two phenomena is not entirely clear. Wages in the textile industry have traditionally been low relative to durable goods and other non-durable goods industries. Over the same period of time, real disposable income has increased, and this is closely associated with improved job opportunities in other industries in which the wage levels have been more responsive to improved economic conditions. One might argue, therefore, that to some extent there has been a shift of labor from 
textiles to better paying jobs. Although the results of equation (5) do not allow one to reach this conclusion directly, they are at least consistent with such a hypothesis.

Equation (5) is subject to some criticism in that a wage variable does not appear as an explanatory factor in determining employment. In fact, it might be argued that equations (5) and (6) should be simultaneously determined, with the dependent variable of (6) appearing also as an explanatory variable in (5). This criticism would be a valid one, and the results of such a solution would shed additional light upon the preceding discussion of the interrelations among income, employment, output, and wages. However, for purposes of this study we have chosen to restrict the model to one suitable for solution by ordinary least squares, and therefore, simultaneous relationships have been deliberately avoided.

Equation (6) relates average earnings per week by production workers to total employment of production workers and a dummy variable representing trend. Both variables are significant at the .01 level. With regard to earnings, the coefficient of the trend term can be interpreted to mean that, net of the effect of changes in employment, there has been, on the average, an annual increase of about seven cents per hour in the earnings of production workers during this twelve-year period, if we assume an average work week of 40 hours.

Prices are explained in equation (7) by the inventories to unfilled orders ratio for the preceding month, average weekly earnings, textile prices in the preceding period, the price index for wool in the preceding period, and a dummy variable representing trend. All five explanatory variables are significant at the .01 level. The negative coefficient associated with the ratio of inventories to unfilled orders expresses the logical and expected relationship between that ratio and textile prices. The coefficient of the trend term indicates that there has been a decline in the index of prices of textile mill products during the twelve-year period. This is explainable in part due to the point in time at which the study began; overall textile prices from about 1954 to the end of our period appear to have been relatively stable.

On logical grounds there are a number of variables other than those appearing in equation (7) which should be investigated in connection with the determination of textile prices. Also it is a curious result that the price of wool, the least important of the three major raw materials, should be the only raw material price appearing in the equation. We have investigated the effect of changes in cotton prices and prices of chemicals which represent the inputs for synthetic fibers. However in no case did either of these prove to be statistically significant. It is perhaps true that, due to controls on cotton prices, there has not been sufficient variation to allow the effect of cotton price changes to reveal any impact on overall textile prices. The period of this study does not cover the introduction of one-price cotton in 1963, although there is reason to believe that even this change was not clearly discernible in the form of lower prices of textile goods. The effect of imports on textile prices was not explicitly taken into consideration in this model, and this is a potential source of weakness in equation (7). Therefore, equation (7) is not completely satisfactory on logical grounds, even though it yields an impressive result statistically. Further development of this model will take into consideration additional means of improvement of the price equation.

A difficulty in connection with equations (8) and (9) is that profit and investment data are available only by quarters. However, a decision was made to allow these equations to stand as they appear in this initial version of the model because on the basis of computer simulation results, presented in [9], equations (8) and (9) performed satisfactorily in generating the time paths of profit and investment over the observed period.

Equation (8) explains aggregate net profits of the industry in terms of textile prices for the current and preceding periods, current textile demand, the inventories to unfilled orders ratio, and average weekly earnings. All variables are significant at the .01 level. For the most part, the results obtained are those which would be expected. In the case of the relationship between average weekly earnings and profit, it should be noted that those periods in which increases in average weekly earnings take place are likely to be periods of increased 
industry activity generally, and thus longer work weeks. One might expect this relationship to differ among industries. The textile industry is lightly unionized, in contrast to industries in which increases in earnings might occur periodically due to union-management agreement. In those cases the reverse relationship might not be unexpected.

Investment, in equation (9), is related to a moving average of textile demand for the preceding twelve months and a trend variable. The former is significant at .01 , and the trend variable at .02 . It is acknowledged that the investment planning period would normally cover a span of time longer than one year prior to a given capital expenditure. However, many investment plans for a current period can be changed on the basis of the previous year's activity. Further study is needed on the question of the appropriate time lag between changes in the level of industry activity and its effect upon investment expenditures. The whole question of expectation which belongs in an investment-determining equation is eliminated due to the lack of information.

The Durbin-Watson statistic, presented for each of the nine behavioral equations, is obtained by the formula

$$
D W=\left[\Sigma\left(u^{*}(t)-u^{*}(t-1)\right)^{2}\right] / \Sigma u^{*}(t)^{2}
$$

where

$$
u^{*}(t)=y(t)-y_{c}(t)
$$

where $y(t)$ is the observed value of a given dependent variable, and $y_{c}(t)$ is its calculated value according to the specified regression equation. Therefore, $u^{*}(t)$ is the estimator of $u(t)$, the error term of the population model for which the given regression equation is an estimate. (See Durbin and Watson [2, 3].)

Theil and Nagar [19] have provided critical values of the Durbin-Watson statistic for the purpose of testing for the presence of positive autocorrelation. These values avoid the "region of ignorance" within which the test is inconclusive, as originally formulated by Durbin and Watson. Thus, as suggested by Theil and Nagar, critical values for $D W$, at the .01 level of significance, were calculated by the formula

$$
\begin{aligned}
D W_{.01} & =2[(n-1) /(n-\Lambda) \\
& -2.32635 / \sqrt{n-2}]
\end{aligned}
$$

where $n$ is the number of observations, and $\Lambda$ is the number of coefficients in the equation, including the constant term.

Therefore, when $D W>D W_{.01}$, the null hypothesis of independence of residuals (i.e., no positive autocorrelation) is accepted at the .01 level. On the basis of this test, we are able to accept the hypothesis for equations (1) apparel demand; (4) output of textile mill products; and (7) prices. $^{5}$ The hypothesis must be rejected for the other six behavioral equations, indicating that significant autocorrelation is present in their residuals. Table 1 , below, gives calculated $D W$ statistics in relation to $D W_{.01}$, obtained by formula (15).

Table 1. - Calculated Values of the Durbin-Watson Statistic and Critical Values for Testing THE NULl Hypothesis OF INDEPENDENCE OF RESIDUALS AT THE .01 LEVEL

\begin{tabular}{crcc}
\hline \hline Equation No. & $D W$ & $D W .01$ & $\begin{array}{c}\text { Decision on } \\
\text { Hypothesis }\end{array}$ \\
\hline$(1)$ & 1.70 & 1.68 & Accept \\
$(2)$ & .96 & 1.64 & Reject \\
$(3)$ & 1.35 & 1.67 & Reject \\
$(4)$ & 1.71 & 1.67 & Accept \\
$(5)$ & .41 & 1.68 & Reject \\
$(6)$ & .50 & 1.64 & Reject \\
$(7)$ & 1.96 & 1.66 & Accept \\
$(8)$ & .98 & 1.67 & Reject \\
$(9)$ & .62 & 1.63 & Reject \\
\hline
\end{tabular}

A commonly followed procedure for the removal of autocorrelation is the transformation of variables to first differences. However, this procedure is satisfactory only when autocorrelation is unity. Accordingly, we have followed the more general transformation procedure suggested by Theil and Nagar [19] for removing the autocorrelation difficulty. This method uses differences over time in the observed values of variables adjusted by the estimated coefficient of autocorrelation. It is assumed that,

$$
u(t)=\rho u(t-1)+\epsilon_{t}
$$

where $\rho$ is the coefficient of autocorrelation, and $\epsilon_{t}$ is the independent normal deviate with

\footnotetext{
${ }^{5}$ Nerlove and Wallis [12] contend that an equation, estimated by ordinary least squares and containing lagged values of the endogenous variables, will yield a DurbinWatson statistic biased toward the value it would have if no serial correlation were present. If their contention is true, we would fail to reject a false hypothesis in the case of equation (7), which contains last month's price as an explanatory variable. We have allowed the equation to stand as is, however, on the ground that simulation results based on equation (7) were highly satisfactory. (See [9]).
} 
constant variance. They suggest that $D W$ is an estimate of $\rho$ (i.e., $\rho^{*}$ ) according to the relationship, $\rho^{*}=1-D W / 2$.

Therefore, for the given regression equation, $y(t)=a+\beta_{1} \mathrm{x}_{1}(t)+\beta_{2} \mathrm{x}_{2}(t)+u(t)$

a transformation of that equation to differences, such as,

$$
\begin{aligned}
y(t) & -\rho y(t-1)=a(1-\rho)+\beta_{1}\left[x_{1}(t)\right. \\
& \left.-\rho x_{1}(t-1)\right]+\beta_{2}\left[x_{2}(t)\right. \\
& \left.-\rho x_{2}(t-1)\right]+[u(t)-\rho u(t-1)]
\end{aligned}
$$

will remove first-order autocorrelation.

Having followed this technique, we obtained new equations for apparel output, demand for textile mill products, employment, earnings, profit, and investment, which are presented and discussed in the final section of this paper.

\section{A Restatement of the Model}

Apparel Demand

$$
\begin{aligned}
D_{A}(t)= & 553.71+300.81[D P I / C P I(t-1)] \\
& (48.8) \\
+ & 96.94\left[A_{D}(t-1)\right] \\
& (12.7) \\
- & 55.19\left[A_{D}(t-2)\right] \\
& (11.3) \\
& 94.38\left[A_{D}(t-3)\right]+34.83[M] \\
& (12.2) \\
R & =.835 \\
F & =62.4
\end{aligned}
$$

Apparel Output (revised)

$$
\begin{gathered}
O_{A}(t)=2.38+33.79\left[I N V_{A}(t-1)\right] \\
\quad(4.19) \\
R=.566 \\
F=64.9
\end{gathered}
$$

Demand for Textile Mill Products (revised)

$$
\begin{aligned}
D_{T}(t)= & .5154+.0073\left[O_{A}(t)\right] \\
& (.0008) \\
- & .0082\left[A O_{A}(t)\right]+.0059[\operatorname{IM}(t)] \\
& (.0011) \\
+ & .0122[M] \\
& (.0020) \\
R & =.0008) \\
F & =53.3
\end{aligned}
$$

Output of Textile Mill Products

$$
\begin{aligned}
O_{T}(t)= & 58.99+41.20\left[D_{T}(t)\right] \\
& (3.2) \\
- & 14.45[I N V / U O(t-1)]-.515[M]
\end{aligned}
$$

$$
\begin{aligned}
& +.082[T] \\
& (.009) \\
& R=\quad .894 \\
& F=137.3
\end{aligned}
$$

Employment of Production Workers (revised)

$$
\begin{aligned}
N_{P T}(t) & =310.65+1.51\left[O_{T}(t)\right] \\
& +.61\left[O_{T}(t-1)\right]+.51\left[O_{T}(t-3)\right] \\
& (.17) \\
- & 356.54[D P I / C P I(t-1)] \\
& (20.0) \\
R & =.845 \\
F & =84.4
\end{aligned}
$$

Earnings (revised)

$$
\begin{aligned}
E_{\bar{w} / m}(t) & =.449+.041\left[N_{P T}(t)\right]+.238[T] \\
R & =. .004) \\
F & =283.5
\end{aligned}
$$

Prices

$$
\begin{aligned}
P_{T}(t)= & 169.07-8.41[I N V / U O(t-1)] \\
& +.5722\left[E_{\bar{w} / m}(t)\right]+.7986\left[P_{T}(t-1)\right] \\
& (.1522) \quad(.0267) \\
+ & .0342\left[P_{w}(t-1)\right]-.0682[T] \\
& (.0093) \\
R & =.983 \\
& F=631.8
\end{aligned}
$$

Profit (revised)

$$
\begin{gathered}
\Pi_{T}(t)=-119.255+1.008\left[P_{T}(t)\right] \\
-.759\left[P_{T}(t-1)\right]+57.412\left[D_{T}(t)\right] \\
\quad(.333) \\
R=.442 \\
F=11.2
\end{gathered}
$$

$$
\begin{aligned}
& \text { Investment }(\text { revised) } \\
& \begin{array}{c}
I_{T}(t)=-.059+.263\left[A D_{T}(t)\right] \\
R=0.083) \\
F=112.6
\end{array}
\end{aligned}
$$

We can accept the model as presented above to be, to the best of our knowledge, free of the influence of first-order autocorrelation. (However, second-order, third-order, etc. autocorrelation may still be present.) Therefore, estimates of parameters should be unbiased as well as efficient. Variables in the revised equations for a given $(t)$ refer to observations in $(t)$ minus observations in $(t-1)$, after adjust- 
ment of the $(t-1)$ observation as explained above. Likewise, variables noted as $(t-1)$ in the revised equations are actually $(t-1)$ $-(t-2)$, after similar adjustment, and so on.

In all cases, $F$ ratios for the revised equations are significant at the .01 level. All variables in the revised equations are significant at the .01 level, with the exception of one, $\left[P_{T}(t-1)\right]$, in equation (8A), which is significant at the .05 level. Variables were not allowed to remain in the revised form unless they were significant at the .05 level. Therefore, some were dropped in the revision.

The variables of logical importance which were eliminated as a result of the revision were: the moving average of apparel demand $\left[A D_{A}\right]$, in equation (2A) determining apparel output; the ratio of inventories to unfilled orders, $[I N V / U O]$, in equation (8A) determining profit; and average weekly earnings $\left[E_{\bar{w} / m}\right]$, also in the profit equation.

Therefore, the result of the revision is that the model loses a degree of its explanatory capability, and in each case, the total correlation of the given equation invariably declines. However, for a number of reasons, we continue to regard the restated model as a satisfactory one.

First, one obtains more richness in the data (i.e., degrees of freedom) by resorting to monthly observations as opposed to, say, annual observations, which is usually done to avoid autocorrelation. Even though doing so magnifies the problem of autocorrelation, this course of action is to be preferred because of the increased explanatory power of the resulting model over that which would otherwise be provided by a much smaller number of observations. This is especially true if, after eliminating the effect of autocorrelation, the model remains significant in all important statistical aspects (as this one does) and continues to contain those variables of logical importance in providing an insight into the behavior of the system. In the latter case, this requirement is still basically met in the revised model.

This model is subject to another test independent of the results presented in this paper. As mentioned earlier in regard to the Naylor, Wallace, Sasser paper [9], the initial version of this model performed satisfactorily in gener- ating the time paths of the dependent variables by computer simulation. In a sense this provides an independent means of verification of the model, and one might argue that autocorrelation is of little consequence if the model is judged to be acceptable as a simulation device, and if that is its purpose.

In a more general sense, however, the purpose of an econometric model is to explain the behavior of an economic system, in this case, the United States textile industry. Thus, in the final analysis, the model is evaluated by criteria other than, or at least in addition to, its performance in simulation.

\section{REFERENCES}

[1] Davis, T. J., Cycles and Trends in Textiles. U. S. Department of Commerce, Business and Defense Services Administration, 1958.

$[\rightarrow$ Durbin, J., and G. S. Watson, "Testing for Serial Correlation in Least Squares Regression," I Biometrika, 37 (1950), 409-428.

$[\rightarrow$ Durbin, J., and G. S. Watson, "Testing for Serial Correlation in Least Squares Regression," II Biometrika, 38 (1951), 159-178.

[4] Ezekiel, M., and K. A. Fox, Methods of Correlation and Regression Analysis. 3rd Ed. New York: John Wiley \& Sons, 1959.

[5] Granger, C. W. J., and M. Hatanaka, Spectral Analysis of Economic Time Series. Princeton: Princeton University Press, 1964.

[6] Hickman, B. G., "Cyclical Fluctuations in the Cotton Textile Industry," Unpublished Ph.D. dissertation, University of California at Berkeley, 1951.

[7] Johnson, H. G., Economic Policies Toward Less Developed Countries. Washington: The Brookings Institution, 1967.

[8] Johnston, J., Econometric Methods. New York: McGraw-Hill, 1963.

[9] Naylor, T. H., W. H. Wallace, and E. Sasser, "A Computer Simulation Model of the Textile Industry," Journal of the American Statistical Association 62 (1967).

[10] Nelson, R. L., Concentration in the Manufacturing Industries of the United States. New Haven: Yale University Press, 1963.

[11] Nelson, R. L., Merger Movements in American Industry, 1895-1956. (NBER General Series No. 66) Princeton: Princeton University Press, 1959.

[12] Nerlove, M., and K. F. Wallis, "Use of the Durbin-Watson Statistic in Inappropriate Situations," Econometrica 34 (1966), 235-238.

[13] Pugh-Roberts Associates, Inc. Advanced Systems Analysis of Textile Industry Problems. (Report to the Textile and Apparel Technology Center, U. S. Department of Commerce.) 1966. 
[14] Stanback, T. M., Jr., "Short Run Instability in the Cotton Broadwoven Goods Industry," Unpublished $\mathrm{Ph}$. D. dissertation, Duke University, 1954.

$[1 \rightarrow$ Stanback, T. M., Jr., "The Textile Cycle: Characteristics and Contributing Factors," The Southern Economic Journal 25 (1958), 174-188.

[16] Stigler, G. J., Capital and Rates of Return in Manufacturing Industries. (NBER General Series No. 78) Princeton: Princeton University Press, 1963.

[17] Textile Economics Bureau, Inc. Textile Organon. 32 (1961) and 37 (1966).

[18] Textile World. New York: McGraw-Hill, 116 (July, 1966).

$[1 \rightarrow$ Theil, H., and A. L. Nagar, "Testing the Independence of Regression Disturbances," Journal of the American Statistical Association, 56 (1961), 793-806.

[20] U. S. Bureau of the Census. Historical Statistics of the United States. 1960.

[21] U. S. Congressional Record. 89th Cong., 2d Session, 1966. 112 (1966), 20077-20116.

[22] U. S. Department of Commerce, Business and Defense Services Administration. U. S. Industrial Outlook, 1966. 1965.

[23] Winston, C., and M. A. Smith, "Income Sensitivity of Consumption Expenditures," Survey of Current Business, 30 (1950), 17-20.

[ $\rightarrow$ Zymelman, M., "A Stabilization Policy for the Cotton Textile Cycle," Management Science, 11 (1965), 572-580.

[25] Zymelman, M., The Cotton Textile Cycle: Its Nature and Trend. U. S. Department of Commerce, 1963. 